\title{
Review on insecticidal and repellent activity of plant products for malaria mosquito control
}

\author{
Damtew Bekele* \\ Department of Biology, College of Natural and Computational Sciences, Debre Markos University, Ethiopia
}

\begin{abstract}
Mosquitoes are well known for their public health importance since they cause major health problems and diseases including malaria. Use of chemical insecticides in controlling malaria and to prevent disease vectored by mosquito has resulted in problems related to the adverse environmental effects for insecticides potential toxicity, high operational cost, community acceptance, and the development of insecticide resistance among the vectors. The factors mentioned above prompted the search for new means of malaria control strategies. Currently, the secondary metabolites of plants (plant extracts and essential oils) of mosquitocidal potential are recognized as potent alternatives to replace the synthetic insecticides in mosquito control programs due to their larvicidal, adulticidal, and repellent properties. In addition, mosquitocides from plant origin can contribute effective, inexpensive and safe method for malaria vector control. This review also showed that the use of indigenous plant-based products by individual and communities can provide as a prophylactic measure for protection against various mosquito-borne diseases. Therefore, plant products utilized as mosquitocides and repellents can serve as a supplementary and/or alternative control measure in combination with the ongoing anti-vector interventions and can also provide a useful tool to promote localized control of persistent malaria.
\end{abstract}

\section{Introduction}

Malaria is the most important mosquito-borne disease and is caused by Plasmodium parasites through an infective bite of female Anopheles mosquitoes. Globally, malaria caused an estimated 219 (range 154-289) million cases and 660,000 (range 490,000-836,000) deaths in 2010. Approximately $80 \%$ of the cases and $90 \%$ of the deaths occur in Africa [1]. According to records from the Ethiopian Ministry of Health $(\mathrm{MOH}), 75 \%$ of the country is malaria's with about $68 \%$ of the total population living in areas at risk of malaria [2]. Thereby, four to five million people are affected by malaria annually [3]. Moreover, $\mathrm{MOH}$ (2012) estimates that there are 5-10 million clinical malaria cases each year [4]. Accordingly, only one million cases are reported at the national level, with 462,623 (55.84\%) examined and 256,487 (23.68\%) confirmed positive by a diagnostic test in 2009/2010. Approximately 70,000 people die of malaria each year in Ethiopia [4].

Thus, one of the approaches for control of these mosquito-borne diseases is the interruption of disease transmission by killing or preventing mosquitoes from biting humans. Attempts to eradicate the mosquito vectors pursued during the past seven decades have so far yielded no tangible results in tropical regions. The development of mosquito resistance to conventional synthetic mosquitocides coupled with their toxicity to non-target animals have prompted the search for new and effective means of mosquito control. Because of these above problems and concerns, the search for new environmentally safe and target-specific insecticides is being conducted all over the world. Also, to find new modes of action and to develop active agents based on natural plant products, efforts are being made to isolate, screen, and develop phytochemicals possessing insecticidal activity. Therefore, plant products with proven mosquito control potential can be used as an alternative to synthetic insecticides or along with other insecticides under the integrated vector control.

Protozoan parasites of the genus Plasmodium enter the bloodstream through the bites of blood-feeding anopheline female mosquitoes
(Anopheles spp.). The main species that cause human disease are $P$. falciparum, $P$. vivax, $P$. ovale, and $P$. malariae, which are found in many areas but are less common outside Africa [5]. Human infection with $P$. knowlesi, a recognized pathogen of non-human primates, has also been described [6]. Among these, P. falciparum are the species responsible for the severe, often fatal, cerebral form of malaria in Africa. Regarding the anopheline fauna of Ethiopia, the most important vector of malaria is An. arabiensis [5]. It is widely distributed in the country and is usually the vector of epidemic malaria. An. arabiensis mainly breeds in small, temporary, and sun-lit water collections such as rain pools. However, it can also breed in a wide variety of other types of water bodies. It is usually an indoor-resting species, but with an exophagic feeding habit.

The second most frequent vector species in the country is $A n$. pharoensis. Its preferred breeding habitats are usually large, permanent water bodies with emergent vegetation, such as swamps and the edges of lakes. Its indoor and outdoor feeding and resting habits are generally similar to that of An. arabiensis [5]. Other secondary vectors are An. funestus and $A n$. nili, which were, in the past, important vectors of malaria in limited areas in Ethiopia; however, they are now extremely scarce and much localized in their distribution [7]. The focus of Anopheles in malaria control is on female adults because only this sex takes blood meals and is of concern to the general public (Table 1).

According to $\mathrm{MOH}$ (2002) [7], the adult female takes her first blood meal after she emerges from the pupal stage. Some species prefer feeding on domestic animals (zoophilic) and some prefer human blood

${ }^{*}$ Correspondence to: Damtew Bekele, Department of Biology, College of Natural and Computational Sciences, Debre Markos University, Debre Markos, P O Box 269, Ethiopia, Tel: +251-912-17-91-24; E-mail: damtish99@yahoo.com

Key words: malaria vector, mosquitocide, repellent

Received: May 07, 2018; Accepted: May 21, 2018; Published: May 25, 2018 
Table 1. An overview of insecticides derived from plants with their targeted system and mode of action

\begin{tabular}{|c|c|c|c|c|c|}
\hline Common name & Class of insecticide & Plant spp. & Targeted system/proc-ess & Mode of action & References \\
\hline Azadirachtin & Botanical from neem oil & $\begin{array}{l}\text { Azadirachta indica and Melia } \\
\text { azadirachta }\end{array}$ & $\begin{array}{l}\text { Growth and } \\
\text { development / } \\
\text { Metabolic } \\
\text { processes }\end{array}$ & $\begin{array}{l}\text { Prothoracicotropic hormone } \\
\text { (PTTH) inhibitor; } \\
\text { Phagostimulant disruptor }\end{array}$ & Paterson (2009) [45] \\
\hline Cinnamaldehyde & Botanical & Cinnamomum camphora & Energy production & $\begin{array}{l}\text { Exact mode of action not well } \\
\text { understood; possibly } \\
\text { interference with glucose } \\
\text { uptake or utilization }\end{array}$ & Brown (2005) [46] \\
\hline Pyrethrins & pyrethrins & $\begin{array}{l}\text { Chrysanthemum } \\
\text { cinerariaefolium }\end{array}$ & Nervous system & $\mathrm{N}^{\mathrm{a}+}$ channel modulators & Arnason et al. (2012) [20] \\
\hline Rotenone & Botanical insecticide & $\begin{array}{l}\text { Derris elliptica, } \\
\text { Lonchocarpus nicou, and } \\
\text { Tephrosia } \text { spp. }\end{array}$ & $\begin{array}{l}\text { Metabolic } \\
\text { processes/ energy } \\
\text { production }\end{array}$ & $\begin{array}{l}\text { Respirator electron transport } \\
\text { inhibitor at site I }\end{array}$ & Roark (1947) [48] \\
\hline Nicotinoids & Botanical & $\begin{array}{l}\text { Nicotiana tabacum.and } \\
\text { Nicotiana rustica }\end{array}$ & neurotoxic & $\begin{array}{l}\text { Blocks acetyl choline } \\
\text { receptor }\end{array}$ & O'brien (1966) [49] \\
\hline
\end{tabular}

(anthropophilic). But they are ready to feed on alternative hosts when the favourite one is not available. The biting condition also varies: some are endophagic (indoor-biting) and others exophagic (outdoor-biting). Regarding resting places, they are frequently inside houses (endophilic) but still some can rest outside the houses (exophilic). Female mosquitoes usually enter house after dark, take a blood meal and fly to a nearby wall or ceiling where they normally rest until all blood is digested and thus ready to fly outside to lay eggs.

\section{Malaria control}

According to WHO (2002) [8], malaria control involves prevention of mosquito bites, killing mosquitoes and treatment of patients. The following can prevent mosquito bites: use of bed nets at night, which are more effective if impregnated with an insecticide; use of mosquito repellents; and screening houses to prevent mosquitoes from entering. In addition, eliminating breeding sites and killing larvae, pupae and adult mosquitoes will help to reduce the number and longevity of vectors. Furthermore, malaria transmitted by vectors that rest indoors can be prevented or controlled by spraying the insides of houses with residual insecticide.

In regards the control of malaria, in Ethiopia until recently relied on vector control through application of chemical insecticides. The discovery of DDT's insecticidal properties in 1939 and the subsequent development of organochlorine and organophosphate insecticides limited natural product research since the answers to insect control were thought to have been found [9]. On the other hand, some inherent features and use patterns of the conventional synthetic insecticides lead to toxicity to mammals including livestock, fish, birds, and beneficial organisms; human poisoning; adverse effects on the environment resulting in contamination of soil, water, and air; resurgence of insect pest populations because of the emergence and spread of physiological and behavioral resistance to a wide range of insecticides; as well as higher costs of spraying operations, and high degree of refusal to permit indoor spraying, has necessitated the utilization of plant products as an alternative methods of vector control for meeting the modern criteria of use in integrated vector management programs.

\section{Secondary metabolites for insecticides and insect repellents}

Secondary metabolites are those natural products which are usually of plant origin derived through enzymatic controlled complex metabolic pathway of primary metabolites [10]. They do not function directly in the primary biochemical activities that support the growth, development and reproduction of the organism in which they occur. The occurrence and distribution of secondary metabolites in plants can be associated with a defensive strategy against herbivores, pathogenic organisms (bacteria and fungi), insects and pests. The higher plants, for example, cannot escape the attacks of their predators, and do not possess an immune system to protect them from challenges by bacteria or viruses. The alternative survival strategy that they evolved is a chemical defence represented by the presence in their cells of allelochemicals, molecules that have a biological activity on interacting organisms [11].

The qualitative and quantitative occurrence of insecticidal constituents of plants is influenced by three principal factors [10]. Genetic effects induce both quantitative and qualitative changes within the limits set by the genetic makeup of the taxon. That is, plants of the same species that resemble one another closely in form and structure may be quite different in their genetic composition that often results in distinct differences with regard to secondary metabolites. Ontogenic factor deals with the concentration of secondary metabolites increase or decrease with the age of the plants, their identity may vary with the stage of development. Environmental factors including soil, altitude, climate (temperature, light, rainfall, wind), biotic or associated flora (fungal, bacteria, and viral infections, presence of insects, and plant density) can also produce quantitative variation in the secondary plant constituents.

Collection of plant material is based on prediction that taxonomically related plants may contain structurally similar compounds. Following collection, several extraction methods are available, the simplest being cold extraction (in a large flask with agitation of biomass using a stirrer), in which the ground dry material is extracted at room temperature with solvents of increasing polarity: first hexane (petroleum ether) then chloroform (or dichloromethane), ethyl acetate, acetone, methanol, and finally water. The main advantage of this cold extraction is that there is little potential degradation of the natural products [10]. Extraction methods used pharmaceutically involves the separation of medicinally active portions of plant tissues from the inactive/inert components by using selective solvents. During extraction, solvents diffuse into the solid plant material and solubilize compounds with similar polarity [12].

Application of larvicide from botanical origin was extensively studied as an essential part of integrated mosquito management, and various mosquito control agents such as ocimenone, rotenone, capllin, quassin, thymol, eugenol, neolignans, arborine and goniothalamin were developed [9]. The chemicals derived from plants have been projected as weapons in future mosquito control program as they are shown to function as general toxicant, growth and reproductive inhibitors, repellents and oviposition-deterrent [13]. Another study by [14] stated that local plants with repellent or insecticidal action may 
play an important role in regions where mosquitoes bite in the early evenings or in situations when there are not enough bed nets to cover all the beds in a house.

With regard to mosquitocidal plants, it has been known that at least 344 species of plants including the neem tree are known to contain bioactive materials that show some mosquitocidal activity [13]. Many of the reported tropical plants came under scrutiny, leading to extraction and characterization of their active constituents, which accounted for various uses by man. The most important of these constituents are alkaloids, terpenoids, steroids, phenols, saponins and tannins [9]. Botanical-based mosquito control can often be obtained from local source and is likely to generate local employment, reduce dependence on expensive imported products, and stimulate efforts to enhance public health.

According to Varma and Dubey (1999) [15], some of the secondary metabolities are merely the end products of aberrant biosynthetic pathways and other excretory products. Plants synthesize a dazzling array of biologically active products. Accordingly, in the case of insects, various plant products affect nerve axons and synapsis (e.g. ryanoidne), respiration (rotenone), hormonal balance (juvenile and molting hormone analogues and antagonists) and behaviour (repellents, antifeedants).

Among the numerous chemical compounds of plants most can be grouped into major chemical categories including nitrogen compounds (primarily alkaloids), terpenoids, and phenolics.

Alkaloids: Alkaloids are basic substances which contain one or more nitrogen atoms, usually in a heterocyclic ring. The distinct chemical property of most alkaloids is their basicity, this property is dependent on the availability of lone pair electrons on nitrogen as described by [10]. Their mode of action varies, but many affect acetylcholine receptors in the nervous system (e.g., nicotine) or membrane sodium channels of nerves (e.g., veratrin), anabasine (Anabasis aphylla), veratrin (Schoenocaulon officinale), and ryanodine (Ryania speciosa). Although these chemicals are not volatile, they may be used as repellents by burning plant material, either on a fire or in a mosquito coil to create an insecticidal smoke that repels the insects through direct toxicity. Alkaloids are found in large quantities in many members of the Berberidaceae, Fabaceae, Solanaceae, and Ranunculaceae families, and all of which are used extensively as traditional insect repellents [16].

Terpenoids: Terpenoids such as ocimenone from the essential oil of Tagetes minuta (Green et al., 1991) [17], thymol from Thymus capitatus oil, and methylchavicol from Ocimum basilicum oil were identified. The terpenoids comprising costunolide, trans-anethole, methyleugenol, iso-methyleugenol, geranial, and neral, in decreasing order of activity, were present in hexane extracts of various parts of Magnolia salicifolia. Monoterpenes and sesquiterpenes are major components of many essential oils. Common examples include myrcene (bay leaves), geraniol (citronella), eucalyptol, also known as cineole (Eucalyptus spp.), and linalool. Open-chain structures include menthol (mint family), camphor (sagebrush), $\alpha$ and $\beta$ pinene, and limonene.

The widely publicised compound Azadirachtin, derived from the neem tree (Azadirachta indica), is a triterpenoid [18]. Azadirachtin and saponins found in the neem tree are insect growth regulators (phytoecdysones). Moreover, the family Asteraceae has many members that contain these compounds and are widely used in mosquito control. The neem oil and neem seed kernels inhibit the formation of mosquito eggs and oviposition in An. stephensi and An. culicifacies [18].
Phenolics: Phenolics are compounds with $\mathrm{OH}$ group attached to an aromatic ring. Important phenolics in terms of insecticidal and repellent function are the flavonoids, which are characteristic compounds of higher plants. There are three important insect repellent flavonoid groups. The flavones are found in the Labatiae, Umbelliferae, and Compositae. The second important group is the isoflavonoids, found mainly in the Leguminosae, an example of which is the insecticidal compound rotenone present in Derris eliptica, and this rotenone is a potent mitochondrial poison. The other main group of phenolics important in repelling insects is the tannins.

\section{Plant derived compounds use for mosquitocides}

Botanicals have been used in various forms to control mosquitoes, for example ancient peoples used smoke from burning cattle or goat dung to drive out mosquitoes from their caves or huts before sleeping [19]. Later on, certain herbs and barks of some trees were added to the smoldering fire to enhance the repellent action of smoke.

Plant products can be used either for killing larvae or adult mosquitoes or as repellents for protection against mosquito bites, depending on the type of activity they possess. A large number of plant extracts have been reported to have mosquitocidal or repellent activity against mosquito vectors [13], but very few plant products have shown practical utility for mosquito control.

Arnason et al. (2012) [20] reported that traditionally used botanical insecticide products include nicotine, rotenone, ryania as shown in Figure 1. Nicotine is a fast-acting nerve toxin; it works as a contact poison (symptons similar to those caused by organophosphate or carbamate insecticides). Acting at the nicotinic acetylcholine receptor it leads to uncontrolled continuous firing of the neuroreceptor. Although nicotine has a long history of use and are effective contact and ingested insecticides they also have extremely high mammalian toxicity and are candidates for regulatory phase out. Rotenone is derived from extracts of the tropical legumes Derris and Lonchocarpus. The main active principle, the isoflavonoid rotenone, is moderately toxic to mammals due to poor absorption and rapid metabolism but is highly toxic to insects and fish; due to its rapid uptake and inhibition of respiratory electron transport at site I. Ryania is an extract of the South American shrub Ryania sp. containing the diterpene alkaloid ryanodine. It exerts its toxicity by blocking $\mathrm{Ca}^{++}$.

The other important group of botanical insecticide is the pyrethrins derived from pyrethrum, which is extracted from dried flowers of Chrysanthemum cinerariifolium. Chemical components of the extract are sesquiterpenes, triterpenes and sterols, flavonoids, $n$-alkanes and fatty acids. The pyrethrins are meroterpenes (mixed biosynthesis: a terpene-derived unit is attached to a non-terpene moiety), esters of the chrysanthemic or pyrethric acid with ketocyclopentene alcohols (Figure 2): pyrethrolone (pyrethrins I and II), cinerolone (cinerins I and II) and jasmolone (jasmolin I and II). Often available at $25-50 \%$ concentration, pyrethrin I and II are present in greatest amounts.

Several groups of phytochemicals such as alkaloids, steroids, terpenoids, essential oils and phenolics from different plants have been reported previously for their insecticidal activities [9]. For instance, Piperaceae is one family that has many promising phytochemicals with insecticidal activity. Regarding Piper secondary plant compounds, they have several modes of action including contact toxicity [22], synergism $[23,24]$ repellent and antifeedant properties.

Palsson and Jaenson (1999) [25] showed that smoldering Hyptis suaveolens provided approximately $84 \%$ protection for 2 hours against 
<smiles>CN1CCCC1c1cccnc1</smiles>

Nicotine

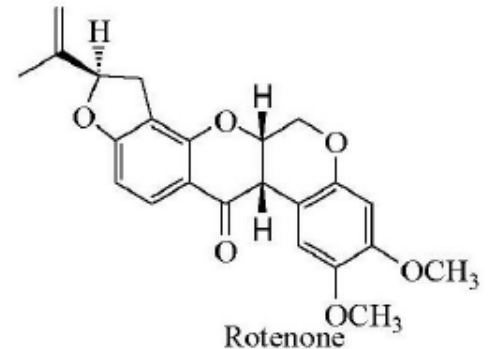

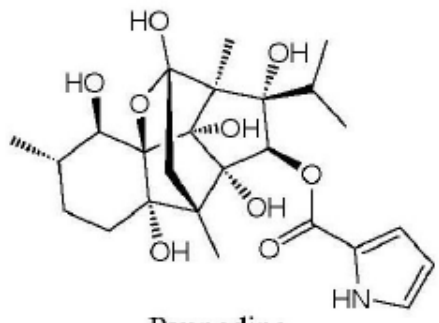

Ryanodine

Figure 1. Botanical insecticides derived from plants (adapted from: Arnason, J. T., Sims, S. R. and Scott, 2012. Natural products from plants as insecticides, Phytochemistry and Pharmacognosy: www.eolss.net/Sample-Chapters/C06/E6-151-)

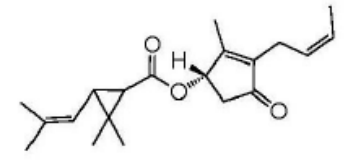

Cinerin I<smiles>CC/C=C\C1C(=O)CC(OC(=O)CC(C)(C)CC(C)C)C1C</smiles>

Jasmolin I<smiles>CCCCC1=C(C)C(OC(=O)CC(C)(C)CC(C)C)CC1O</smiles>

Pyrethrin I

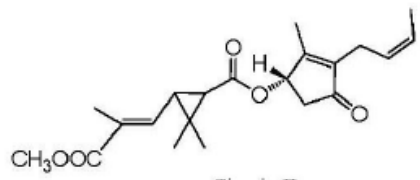

Cinerin II<smiles>[2H][C@]1(OC(=O)C2C(C=C(C)C(=O)OC)C2(C)C)CC(=O)C(C/C=C\CC)=C1C</smiles>

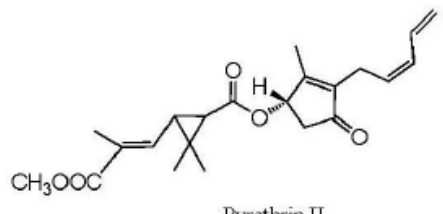

Pyrethrin II
Figure 2. Pyrethrins from Chrysanthemum pyrethrum (adapted from: Arnason et al., 2012)

An. gambiae, whereas Seyoum et al. (2002b) [26] found only a $20.8 \%$ reduction in biting. Mosquito repellent chemicals are also contained in the Mentha spp., including menthone, limonene, beta pinene, alpha pinene, and linalool [27]. Fumigants evaporated using heat or mosquito coils containing the plant may repel and kill mosquitoes. Evaporating the pure essential oil with a kerosine lamp caused a $51.94 \%$ reduction in mosquito biting in field trials.

Work using the related Lippia uckambensis by Seyoum et al. (2002a) [28] has shown that the release of volatiles from the leaves through thermal expulsion reduces An. gambiae biting by $49.5 \%$. The repellency of neem oil to hematophagous insects has been tested, although the results have been variable. Burning and thermal expulsion of the leaves produce only a modest reduction $(<25 \%)$ in biting [26]. However, experiments using neem oil derived from the seeds have shown better protection. Sharma et al. (1993) tested neem oil in coconut oil against An. culicifacies at concentrations of $0.5,1.0$, and $2 \%$ [29]. Two percent oil was reported to provide $100 \%$ protection for 12 hours. In addition, the leaves of Lantana camara are repellent, giving $42.4 \%$ protection against An. gambiae when used as an ambient repellent [28].

In the study carried out on the larvae of Ae. aegypti and $C x$. pipiens pallens, methanolic extract of $P$. longum fruits possessed a strong mosquito larvicidal activity at $40 \mathrm{ppm}$ [30]. The same author stated that bioassay-guided fractionation of the P. nigrum fruit extract exhibited four active constituents identified by spectroscopic analyses as pellitorine, guineensine, pipercide, and retrofractaminde A (Figure 3). Among the four test compounds, pipercide had a potent larvicidal activity against larvae of $C x$. pipiens pallens with $\mathrm{LD}_{50}$ value of 0.004 ppm. On the basis of $\mathrm{LD}_{50}$ values, the compound most toxic to $C x$. pipiens pallens larvae was pipercide followed by retrofractaminde $\mathrm{A}$ $\left(\mathrm{LD}_{50}, 0.028 \mathrm{ppm}\right)$, guineensine $\left(\mathrm{LD}_{50}, 0.17 \mathrm{ppm}\right)$, and pellitorine $\left(\mathrm{LD}_{50}\right.$, $0.86 \mathrm{ppm})[30]$.

According to Kaou et al. (2010), the aerial part of Piper capense L. is traditionally used in Comoro Islands for diarrhoea and cough [31]. The chloromethylenic extract of $P$. capense has shown moderate in vitro activity against $P$. falciparum. The phytochemical studies carried out on $P$. capense have resulted in the identification of lignans, sesquiterpenes, and essential oil with high percentage of monoterpene hydrocarbons. The chloromethylenic extract of $P$. capense have showed the presence of a new amide alkaloid, Kaousine together with the $\mathrm{Z}$ form of antiepilepsirine, the known apigenine dimethylether, and piperchabamide $\mathrm{A}$, isolated for the first time from this plant. Amides may also have a strong larvicidal activity, such as piperine and piperidine, present in acetone extracts of Piper nigrum seeds. Piperine was observed to be a more active larvicide than piperidine. The activity of pipernonaline, a piperidine alkaloid isolated from Piper longum fruits, was found to be comparable to those of some organophosphorous insecticides [32]. Another study by $\mathrm{Su}$ and Horvat (1981) [33] reported several insecticidal amides, such as pipericide, (E,E)-N-(2- methylpropyl)-2,4,12 tridecadienamide, and (E,E,E)-11-(1,3- benzodioxol-5-yl)-N-(2-methylpropyl)-2,4,10undecatrienamide, which have been isolated from P. nigrum.<smiles>CCCCCC=CC=CC(=O)NCC(C)C</smiles>

Pellitorine<smiles>CC(F)CNC(=O)C=CC=CCCCCCC=Cc1ccc2c(c1)OCO2</smiles><smiles>CC(C)CNC(=O)/C=C/C=C/OCCCC=Cc1ccc2c(c1)OCO2</smiles>

Pipercide<smiles>O=C(C=CC=CCCC=CC1=CC2=C(CCC2)OCO1)NCC(F)F</smiles>

Retrofractamide A

Figure 3. Chemical structure of bioactive constituents derived from Piperaceae fruit (adapted from: Lee, 2005) [30] 
The other most commonly studied plants for control of mosquitoes is Azadirachta indica, (Meliaceae). According to Nagpal et al. (1995) [34], control of mosquito breeding has been demonstrated in the field in some confined habitats using indigenous methods of application of neem oil in water and neem oil coated on wooden scraps. In their field study, wood scrap balls soaked in 5 to $20 \%$ neem oil in acetone were tested in overhead tanks of 0.50 cubic meters against An. stephensi breeding. Though it did not prohibit ovipostion, it arrested pupal formation and eventually the adult emergence for about 45 days. In terms of its mode of action, neem has been shown to target the cholinergic system in insects through inhibition of acetylcholinestrase.

\section{Use of plant products for mosquito repellents}

Many popular practices exist to avoid the deadly disease carried by mosquitoes and nuisance of mosquito bites such as fumigation, burning green leaves on the hut's threshold, mosquito coils, insecticide sprays, and repellents. For example, smoke is a common method of repelling biting mosquitoes that is used throughout the world [35]. Fresh or dried plants are frequently added to fires to enhance the repellent properties of the smoke. Also, this repellency of plant material has been exploited for thousands of years by man, most simply by hanging bruised plants in houses, a practice that is still in wide use throughout the developing countries [36]. Therefore, utilizing homegrown repellents may reduce the need for foreign imports where exchange rate inequalities and transport costs inflate expenditure. Plants have also been used in the form of crude fumigants where plants were burnt to drive away nuisance mosquitoes and later as oil formulations applied to the skin or clothes. Many of the fumigants used produce smoke that is obnoxious to man, and thus was assumed to be repellent to insects. It has also been shown that when applied topically at $2 \%$ strength in a base of coconut oil, neem oil provides $100 \%$ protection against biting by all Anopheles species during a 12-hour period [29].

Mosquito coils made from dried plants and combustible materials such as sawdust are also a cheap and often an effective method of repelling mosquitoes. As well as being cheap and locally available, natural repellents are normally culturally acceptable and locally known. On the other hand, the use of smoke as a repellent is not desirable due to the respiratory problems it can cause. However, the protection from malaria this practice may provide goes some way to balance out the health risks associated with this method, particularly as the primary use of the fires is for cooking [37]. A possible new, low-technology method to release plant volatiles is thermal expulsion where the plant material is placed on a metal plate over a fire [26]. It appears to provide greater repellency than direct burning of plant material, possibly since it releases different repellent compounds, and may carry a lower risk of causing respiratory disease since less smoke is produced this way.

Repellents as a method of preventing malaria are particularly promising in regions where vector mosquitoes bite early in the evening and in regions where vector mosquitoes have exophagic (outdoor) feeding habits, so that bed net use is unlikely to be very effective [35]. They are also important where drug resistant parasites and insecticide resistant vectors prevail. However, traditional repellents would have disadvantages, as they tend to last for a shorter period than synthetic preparations such as DEET (N, N-diethyl-m-toluamide), therefore necessitating frequent reapplication. Other disadvantages include strong odors, skin irritation, and possible health effects when they have not been evaluated for toxicity.

Carbon dioxide, excretory products and lactic acid present in sweat in warm blooded animals act as an attractive substance for female mosquitoes. The perception of the odor is through chemoreceptors present in the antennae of mosquitoes. However, the repellents block the lactic acid receptors thus destroying upwind flight and as a result the mosquitoes lose its contact with the host [38]. Therefore, insect repellents work by masking human scent, or by using a scent which insects naturally avoid. Omolo et al. (2004) [39] evaluated six plant species growing in the Kenyan coast for repellency on the forearms of human volunteers against An. gambiae. The results showed that some of these constituents from the different oils, such as R-pinene, limonene, $\gamma$-terpinene, and R-terpinene, showed high individual repellencies. Essential oils that have indicated adult repellency have also been shown to function as larvicides, indicating a cross-functional potential for utilizing these natural products [40].

\section{Essential oils for repellent activity}

Essential oils are derived by steam distillation from plants in several families. The Lamiaceae family includes basil (Ocimum basilicum), mint (Mentha spp.), hyptis (Hyptis suaveolens), lavender (Lavandula spp.), sage (Salvia spp.), and thyme (Thymus spp.). The Myrtaceae family includes eucalyptus (Eucalyptus spp.) and tea tree (Melaleuca spp.), and the Poaceae includes citronella, lemongrass, and palmarosa (Cymbopogon spp.). Direct toxicity, oviposition and feeding deterrence, repellency or attraction appear to result from interaction with the insect nervous system, either by acetylcholinesterase inhibition or antagonism of the octopamine receptors. Rosell et al. (2008) [41] described the oils consist of complex mixtures (hydrocarbon or oxygenated mono and sesquiterpenes; aliphatics; aromatics) with a few major constituents such as 1, 8-cineole (rosemary, eucalyptus), menthol (mints), pulegone (pennyroyal), and eugenol (clove) as shown in Figure 4.

Tawatsin et al. (2001) [42] found that the steam distillate of turmeric plants provided 8 hours protection against Anopheles dirus, and a hexane fraction of galangal provided 3 hours protection from Aedes aegypti in cage experiments [43]. Also, p-menthane-3, 8-diol (PMD) was discovered in the waste distillate of the extract of the lemon eucalyptus plant, which was determined to be the active ingredient for the repellent activity of mosquitoes. It was the effective repeller of mosquitoes.

In another study, Cymbopogon excavates is used in South Africa as a mosquito repellent. When evaluated in the laboratory against $A n$. arabiensis by Govere et al. (2000) [44], it gave good protection for 2 hours, but declined to $59.3 \%$ after 4 hours. This compares favorably with C. nardus. The use of the Cymbopogon genus as an insect repellent is widespread and it has many advantages for use in the prevention of malaria in areas of low transmission, where vector species are active early in the evening. The repellent oils are effective provided that they are reapplied frequently. Four hours' protection may be sufficient if people use the repellents before retiring to a bed net. The grasses grow readily and rapidly throughout much of the Tropics, and a simple steam distillation is sufficient to extract the repellent fractions. The plants in this family are pleasant smelling and are widely used in traditional medicine, making them acceptable for use. In addition, their high citronellal content makes the plants of this genus potential candidate for PMD production since citronellal is a precursor of this molecule.

\section{Mode of action of bioactive compounds from plants for mosquito control}

Among different compounds isolated from different parts of the neem tree, limonoids (tetranortriterpenoids) are considered the most biological active on insects. Azadirachtin, in particular, is a highly oxidized limonoid with many reactive functional groups in close 
proximity to each other, and many isomers were identified (from azadirachtin A to $G$ ), among which the most abundant in the plant tissues are the azadirachtins A and B [45] as indicated in Figure 5. A number of bioactive components have been isolated from various parts of the neem tree, among which azadirachtin (AZ) $\left(\mathrm{C}_{35} \mathrm{H}_{44} \mathrm{O}_{16}\right)$ is the major component. Azadirachtin-B (3-tigloylazadirachtol) is present at concentrations of up to $15 \%$ of the total AZ.

Other AZ analogues such as AZ-C through AZ-G occur at much lower concentrations. Azadirachtin acts as both a feeding deterrent and a growth regulator. In this case, feeding is affected through azadirachtin's interference with phagostimulants, which play a role in normal feeding<smiles>Cc1ccc(C(C)C)c(O)c1</smiles>

thymol<smiles>CC1=CCC(C(C)(C)O)CC1</smiles><smiles>CC(C)[C@H]1CC[C@@H](C)C[C@H]1O</smiles>

$(-)-$ menthol<smiles>C=C(C)[C@H]1CC[C@]2(C)CC[C@H]1C2</smiles><smiles>CC(C)=C1CC[C@@H](C)CC1=O</smiles>

(+)-pulegone

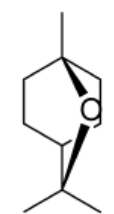

$(+)-\alpha$-terpineol trans- $\beta$-terpineol 1,8-cineole (eucalyptol)<smiles>C=CCc1ccc(O)c(OC)c1</smiles>

eugenol

Figure 4. Essential oils components (adapted from: Rosell et al., 2008) [42]

Azadirachtin A

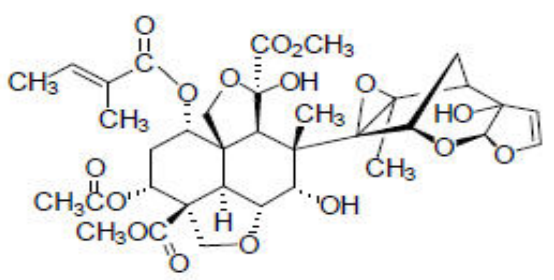

Azadirachtin B

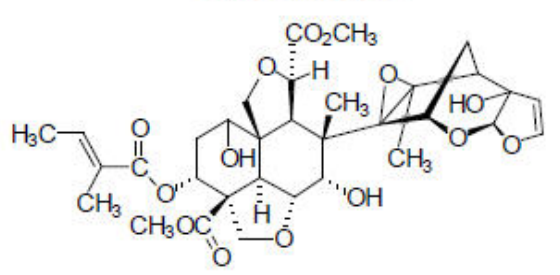

Figure 5. Azadirachtin A and B (Adapted from: Paterson, 2009) [46] behavior of mosquitoes [46]. Neem products are capable of producing multiple effects in insects such as repellent, growth regulator, antioviposition, reduces adults fecundity and eggs vitality.

Azadirachtin can efficiently interfere with insect reproduction, altering the normal sexual development and gametogenesis processes, both at the larval and at the adult stage. The mechanism of action of azadirachtin seems to consist in an interference with the endocrine system: both ecdysteroids and juvenile hormone synthesis are altered by azadirachtin, probably not only by toxic effects on hormoneproducing organs, but also at the brain neurosecretory system level [45]. Azadirachtin affects ecdysteroid and juvenile hormone titers, resulting in severe growth and molting aberrations. The neuropeptides regulating ecdysteroid and JH production may be affected. Disruption of molting leads to formation of larval-pupal, nymphal-pupal, nymphal-adult, and pupal-adult intermediates [47].

This review has attempted to identify secondary metabolites of plants use with its mode of action in controlling mosquitoes. Since plants constitute a potential source of bioactive compounds and generally are free from harmful side effects, use of these botanicals in mosquito control could reduce the cost of synthetic insecticides in malaria control, and also reduce environmental toxicity.

\section{References}

1. WHO (2013) Malaria entomology and vector control Geneva: World Health Organisation, 180

2. MOH (1999) Malaria and Other Vector-borne Diseases Control Unit. Addis Ababa, Ethiopia: Federal Ministry of Health of Ethiopia 59.

3. $\mathrm{MOH}$ (2004) Guideline for malaria epidemic prevention and control in Ethiopia. 2nd edition. Addis Ababa, Ethiopia: Federal democratic Republic of Ethiopia, Ministry of Health, 52 .

4. MOH (2012) President's malaria initiative: malaria operational plan, Ethiopia, 57

5. Abose T, Yeebiyo Y, Olana D, Alamirew D, Beyene Y, et al. (1998) Re-orientation and definition of the role of malaria vector control in Ethiopia. World Health Organization, Division of Control of Tropical Diseases PP. 31.

6. Hellemond JV, Rutten M, Koelewijn R, Zeeman A, Verweij JJ, et al. (2009) Human Plasmodium knowlesi infection detected by rapid diagnostic tests for malaria. Emerg Infec Dis 15: 1478-1480. [Crossref]

7. MOH (2002) Guideline for malaria vector control in Ethiopia. Malaria and othe vector-borne diseases prevention and control Department. Addis Ababa, Ethiopia, 62.

8. WHO (2002) Malaria entomology and vector control. Geneva: World Health Organisation 112.

9. Shaalan EAS, Canyonb D, Younesc MWF, Abdel-Wahab H, Mansour AH (2005) A review of botanical phytochemicals with mosquitocidal potential. Environ Int 31: 11491166. [Crossref]

10. Debella A (2002) Manual for phytochemical screening of medicinal plants. EHNRI, Addis Ababa, Ethiopia, 84 .

11. Martin GJ (1995) Ethnobotany: A methods manual. Chapman and Hall, London, UK, Great Britain University Press, Cambridge Press, 267. [Crossref]

12. Handa SS, Khanuja SPS, Longo G, Rakesh DD (2008) Extraction technologies for medicinal and aromatic plants. International centre for science and high technology $21-25$.

13. Sukumar K, Perich MJ, Boobar LR (1991) Botanical derivatives in mosquito control: a review. J Am Mosq Control Assoc 7: 210-237. [Crossref]

14. Waka M, Hopkins RJ, Curtis C (2004) Ethnobotanical survey and testing of plants traditionally used against hematophagous insects in Eritrea. J Ethnopharmacol 95: 95101. [Crossref]

15. Varma J, Dubey NK (1999) Botanical products as insecticides and fungicides. Curr Sci 76: 172-179.

16. Secoy DM, Smith AE (1983) Use of plants in control of agricultural and domestic pests. Econ Bot 37: 2857. 
17. Green MM, Singer JM, Sutherland DJ, Hibben CR (1991) Larvicidal activity of Tagetes minuta (marigold) toward Aedes aegypti. J Am Mosq Control Assoc 7: 282286. [Crossref]

18. Dhar R, Dawar H, Garg S, Basir SF, Talwar GP (1996) Effect of volatiles from neem and other natural products on gonotrophic cycle and oviposition of Anopheles stephensi and An. culicifacies (Diptera: Culicidae). J Med Entomol 33: 195-201. [Crossref]

19. Kihampa C (2011) Tanzanian botanical derivatives in the control of malaria vectors: opportunities and challenges. J Appl Sci Environ Manag 15: 155-160.

20. Arnason JT, Sims SR, Scott IM (2012) Natural products from plants as insecticides, phytochemistry and pharmacognosy: www.eolss.net/Sample-AllChapter. aspx/C06/ E6-151.

21. Scott IM, Gagnon N, Lesage, L, Philoge'ne BJR, Arnason, JT (2005) Efficacy of botanical insecticides from Piper spp. (Piperaceae) extracts for control of European chafer (Coleoptera: Scarabaeidae). J Econ Entomol 98: 845-855. [Crossref]

22. Scott IM, Puniani E, Durst T, Phelps D, Merali S, et al. (2002) Insecticidal activity of Piper tuberculatum Jacq. extracts synergistic interaction of piperamides. Agric For Entomol 4: 137-144.

23. Scott IM, Jensen H, Scott JG, Isman MB, Arnason JT, Philoge'ne BJR (2003) Botanical insecticides for controlling agricultural pests: piperamides and the Colorado potato beetle Leptinotarsa decemlineata Say (Coleoptera: Chrysomelidae). Arch Insect Biochem Physiol 54: 212-225. [Crossref]

24. Palsson K, Jaenson TG (1999) Plant products used as mosquito repellents in Guinea Bissau, West Africa. Acta Trop 72: 39-52. [Crossref]

25. Seyoum A, Palsson K, Kung'a S, Kabiru EW, Lwande W, et al. (2002b) Traditional use of mosquito-repellent plants in western Kenya and their evaluation in semifield experimental huts against Anopheles gambiae: ethnobotanical studies and application by thermal expulsion and direct burning. Trans R Soc Trop Med Hyg 96: 225-231. [Crossref]

26. Lee SE, Lee BH, Choi WS, Park BS, Kim JG, et al. (2001) Fumigant toxicity of volatile natural products from Korean spices and medicinal plants towards the rice weevil, Sitophilus oryzae. Pest Manage Sci 57: 548-553. [Crossref]

27. Seyoum A, Kabiru EW, Lwande W, Killeen GF, Hassanali A, et al. (2002a) Repellency of live potted plants against Anopheles gambiae from human baits in semi-field experimental huts. Am J Trop Med Hyg 67: 191-195. [Crossref]

28. Sharma VP, Ansari MA, Razdan RK (1993) Mosquito repellent action of neem (Azadirachta indica) oil. J Am Mosq Control Assoc 9: 359-360. [Crossref]

29. Lee HS (2005) Pesticidal constituents derived from Piperaceae fruits. Agric Chem Biotechnol 48: 65-74.

30. Kaou AM, Mahiou-Leddet V, Canlet C, Debrauwer L, Hutter S, et al. (2010) New amide alkaloid from the aerial part of Piper capense L.f. (Piperaceae). Fitoterapia 81: 632-635. [Crossref]
31. Lee SE (2000) Mosquito larvicidal activity of pipernonaline, a piperidine alkaloid derived from long pepper, Piper longum. J Am Mosq Control Assoc 16: 245-247. [Crossref]

32. Su HCF, Horvat R (1981) Isolation, identification and insecticidal properties of Piper nigrum amides. J Agric Food Chem 29: 115-118.

33. Nagpal BN, Srivastava A, Sharma VP (1995) Control of mosquito breeding using wood scrapings treated with neem oil. Indian J Malariol 32: 64-69. [Crossref]

34. Moore SJ, Lenglet AD (2004) An overview of plants used as insect repellents. CRC Press, LLC.

35. Moore SJ, Lenglet A, Hill N (2006) Plant-Based Insect Repellents. In: Insect Repellents Principles methods, and use. Boca Raton Florida: CRC Press. [Crossref]

36. van der Hoek W, Konradsen F, Dijkstra DS, Amerasinghe PH, Amerasinghe FP (1998) Risk factors for malaria: a microepidemiological study in a village in Sri Lanka. Trans $R$ Soc Trop Med Hyg 92: 265-269. [Crossref]

37. Hallem EA, Nicole Fox A, Zwiebel LJ, Carlson JR (2004) Olfaction: mosquito receptor for human-sweat odorant. Nature 427: 212-213. [Crossref]

38. Omolo MO, Okinyo D, Ndiege IO, Lwande W, Hassanali A (2004) Repellency of essential oils of some Kenyan plants against Anopheles gambiae. Phytochemistry 65 2797-2802. [Crossref]

39. Zhu J, Zeng X, O'Neal M, Schultz G, Tucker B, et al (2008) Mosquito larvicida activity of botanical-based mosquito repellents. J Am Mosq Con Assoc 24: 161-168. [Crossref]

40. Rosell G, Quero C, Coll J, Guerrero A (2008) Biorational insecticides in pest management. J Pestic Sci 33: 103-121.

41. Tawatsin A, Wratten SD, Scott RR, Thavara U, Techadamrongsin Y (2001) Repellency of volatile oils from plants against three mosquito vectors. $J$ Vector Ecol 26: 76-82. [Crossref]

42. Choochote W, Kanjanapothi D, Panthong A, Taesotikul T, Jitpakdi A, et al. (1999) Larvicidal, adulticidal and repellent effects of Kaempferia galanga. Southeast Asian J Trop Med Public Health 30: 470-476. [Crossref]

43. Govere J, Durrheim DN, Du Toit N, Hunt RH, Coetzee M (2000) Local plants as repellents against Anopheles arabiensis, in Mpumalanga Province, South Africa. Cent Afr J Med 46: 213-216. [Crossref]

44. Paterson P (2009) Neem the wonder tree: Its pesticide and medicinal applications. Pp. 56.

45. Brown AE (2005) Mode of action of insecticides and related pest control chemicals for production agriculture, ornamentals and turf. Pesticide information leaflet No. 43,13.

46. Beckage NE (2000) Insect growth regulators. In: Rechcigel JE, Rechcigel NA (Eds) Biological and biotechnological control of insect pests. CRC press, PP: 123-137.

47. Roark RC (1947) Some promising insecticidal plants. Econ Bot 1: 437-445.

48. O’Brien RD (1966) Mode of action of insecticides. Annu Rev Entomol 11: 369-402. [Crossref]

Copyright: (C2018 Bekele D. This is an open-access article distributed under the terms of the Creative Commons Attribution License, which permits unrestricted use, distribution, and reproduction in any medium, provided the original author and source are credited. 